\title{
THE CHEMICAL, TOXICOLOGICAL AND ECOLOGICAL STUDIES IN ASSESSING THE HEAVY METAL POLLUTION IN LE AN RIVER, CHINA
}

\author{
MENGCHANG HE*, ZIJIAN WANG $\dagger$ and HONGXIAO TANG \\ State Key Laboratory of Environmental Aquatic Chemistry, Research Center for Eco-Environmental \\ Sciences, Beijing, 100085, P.R. China
}

(First received October 1996; accepted in revised form June 1997)

\begin{abstract}
By integrating the chemical, toxicological and ecological data, the impact of heavy metal pollution on the Le An River was assessed. The results showed that the water and sediment pollution has affected the aquatic ecosystem due to discharges from Dexing copper mines and mines along the Jishui River. The ecological deterioration between the Dexing copper mine and the converges with the Jishui River could be attributed to acid drainage instead of extremely high content of metals in the sediment (non-bioavailable), while that between the Jishui River and downstream $34 \mathrm{~km}$ could be attributed to multi-metal contamination. Sediment pollution associated with the moderate biological and ecological deterioration prevails in downstream of the river as far as the delta area of the lake. (C) 1998 Elsevier Science Ltd. All rights reserved
\end{abstract}

Key words - heavy metals, pollution, toxicity, ecological deterioration, integration

\section{INTRODUCTION}

Chemical, toxicological and ecological approaches have been studied extensively in assessing impacts of trace metal pollution in aquatic environments. Each of these approaches has its inherent limitation. The analytical and/or physicochemical approaches that are used in the assessment of contamination, as well as being complex and costive, are tedious and time-consuming. Additionally, the results obtained do not yield directly the biological toxic potentiality of a given water body (Kramer and Botterweg, 1991), which could not be disclosed in a single evaluation. Numerous studies have demonstrated that the determination of metal concentrations in suspended matters and sediments are more sensitive than the dissolved concentrations when used as indicators of contamination in hydrologic systems (Luoma, 1990). However, total metal concentrations in sediments do not necessarily reflect concentrations that are available to biota. Aquatic organisms have been used in comparative monitoring of pollution effects in different systems and to locate sources of toxicants (Phillip, 1989). Bio-monitoring approach has proved to be promis-

*Present address: State Key Laboratory of Environmental Aquatic Chemistry, Research Center for EcoEnvironmental Sciences, P.O. Box 2871, Beijing 100085 , P.R. China.

†To whom all correspondence should be addressed (Email:wangzj@mail.rcees.ac.cn). ing as a reliable means of quantifying biological effects of complex effluents (Birge et al., 1985). Actually, impact of adverted effects on ecosystem level involves the characteristics of plankton (Cairns, 1980; Monteiro et al., 1995) and benthonic community structure and the succession of the prominent species (Yang, 1987; Leland et al., 1989; Qi and Huang, 1993). The ecological data, however, reflects the integrated characteristics of a system, also including growth environment, ages of species, seasonal physiological cycles, acclimation and genetic adaptation, flood and drain period, and so on.

Principally, physicochemical data of the receiving waters (which could vary with time) can reflect variation of chemical composition of the water caused by discharges, when comparing with background and/or water quality criteria. To a lesser extent, it reflects also the bioavailability (Luoma, 1983). Bioassays are an ideal complementation to the analytical data when employed in evaluating toxicity of the taken water samples or in in-situ. They are considered to be the most reproducible, sensitive, simple, economical and rapid way to evaluate toxicity (Soomi et al., 1990; Kramer and Botterweg, 1991). However, the observed toxicity may not be caused by the pollutants in concerns and the evaluation based on limited species cannot be successfully used to predict the ecological consequences. The ecological variation could be due to variation of the regional or even global environment. Less work has been carried out for the comparison and 
integration of chemical, toxicological, as well as ecological, studies for the heavy metal pollution in rivers (Wesley et al., 1989).

The major objective of this paper was to compare and to integrate the data from different disciplinary studies for assessing the impact of heavy metal pollution in the Le An River.

\section{MATERIALS AND METHODS}

Sampling locations and description of the area

The research area and sampling location are schematically shown in Fig. 1. Site A01 is upstream of the river and apart from the major mines. Site A04 is at $20 \mathrm{~km}$ downstream from A01, where the largest open-cast copper mine in China, Dexing copper mine, is located and whose discharges flow into the Le An River at the converges with the Dawu River (DWR). Site A05 is at $20 \mathrm{~km}$ downstream of site A04. Site A07 is at $50 \mathrm{~km}$ downstream and converges with the Jishui River (J.R., $39 \mathrm{~km}$ long), which is another metal-polluted river along with several small sulfide mines and smelters. Site A08 and A13 are at 84 and $159 \mathrm{~km}$, respectively. Site Al6 is at $230 \mathrm{~km}$ downstream and in the delta area of Poyang lake, the largest fresh water lake in China.

The rainy season in this area begins in April and finishes in September, during which time occurs $60-75 \%$ of annual rainfall and most storm floods. From October to March, less rainfall could be observed and the flow rate in the Le An River is relatively lower (dry season).

\section{Data collection and processing}

All data for river water, sediment, aquatic organisms and from toxicity bioassays were collated from the database of the Cooperative Ecological Research Program (CERP) and relevant publication (Lin, 1992; Tang et al., 1994; Müller and Tang, 1996).

To obtain the chemical data, river water and sediment samples were taken in June 1993 (rainy season) and in October 1994 (dry season), respectively. $\mathrm{pH}$ was measured in situ. Water samples were filtered through $0.45 \mu \mathrm{m}$ membrane in situ and acidified immediately. Sediment samples were taken by Veen grab sampler and were wet-digested after being dried in room temperature. Analysis for heavy metal in soluble samples was performed by FT-AAS (PE-3100 Atomic Absorption Spectrometer).

Water quality index was calculated using the Nemerow index as follows:

$$
\mathrm{PI}=\sqrt{\frac{\left[\frac{C_{i}}{S_{i}}\right]_{\max }^{2}+\left[\frac{C_{i}}{S_{i}}\right]^{2}}{2}}
$$

Where $C_{i}$ is concentration of metal $_{i}$ in river water, $S_{i}$ is national water quality criterion for metal $i$ (NS-SW-88 for type II water, GB 3838 or water quality criteria for aquatic culture, TJ-35-79).

To classify the sediment pollution for single metal, metal concentration in sediments was transformed into enrichment factor (ERF), defined as the ratio of metal concentration to its averaged background concentration. An ecological risk index (RI) has been used as a diagnostic tool for the potential sediment pollution (Lars, 1980) as follows:

$$
\mathrm{RI}=\sum_{i=1}^{n} \mathrm{E}_{r}^{i}=\sum_{i=1}^{n} \mathrm{~T}_{r}^{i} \bullet \mathrm{C}_{f}^{i}=\sum_{i=1}^{n} \mathrm{~T}_{r}^{i} \bullet \mathrm{C}_{s}^{i} / \mathrm{C}_{n}^{i}
$$

Where RI is the requested potential ecological risk index; $\mathrm{E}_{r}^{i}$ is the potential ecological risk factor for a given substance $i ; \mathbf{T}_{r}^{i}$ is the "toxic-response" factor for the given substance, i.e. $\mathrm{Cu}=\mathrm{Pb}=5, \mathrm{Zn}=1 ; \mathrm{C}_{f}^{i}$ is the contamination factor; $\mathrm{C}_{s}^{i}$ is the metal content in superficial sediments; $C_{n}^{i}$ is the regional background concentrations of heavy metals in sediment.

Samples of crustacean, rotifer, and algae for qualitative analysis were collected by phytoplankton net with a mesh size of $50 \mu \mathrm{m}$ from the surface water. Polyurethane foam cut into identical units (PFU-5 $\times 7 \times 8 \mathrm{~cm}$ ) was used as artificial substrates for colonization of protozoan communities (Xu et al., 1994). Benthonic macroinvertebrates were collected with a $0.05 \mathrm{~m}^{2}$ Peterson grab at each sampling

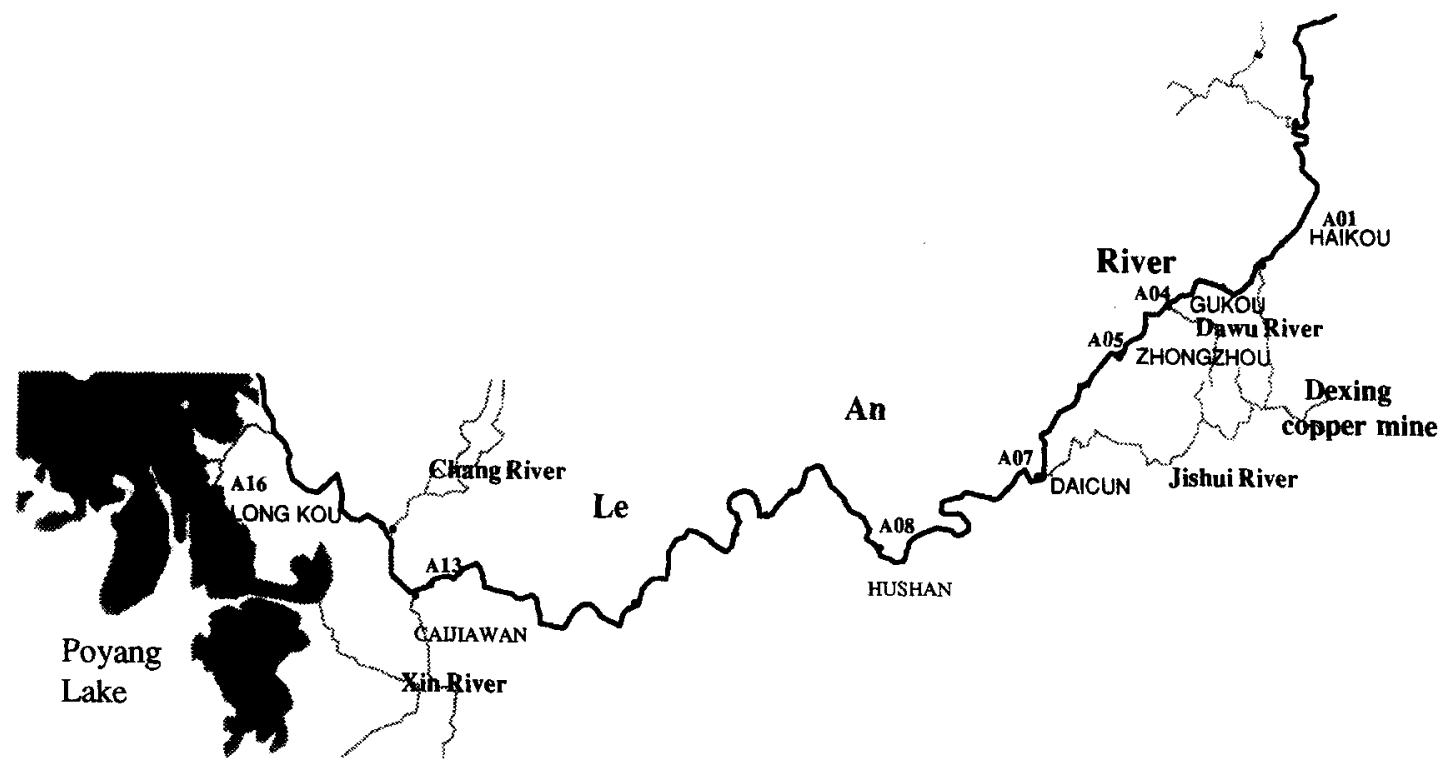

Fig. 1. Research area and sampling location. 
Table 1. Hierarchical model for chemical, ecological and toxicological assessments

\begin{tabular}{lccccc}
\hline Description & Class & Nemerow index (PI) & Risk index (RI) & Diversity index* & $\begin{array}{c}\text { Relative inhibition or } \\
\text { death rate (\%) }\end{array}$ \\
\hline No-effect & 1 & $<1$ & $<20$ & 1.0 & No effect \\
Slightly affected & 2 & $1-2$ & $20-80$ & $0.75-1.0$ & $0-25 \%$ \\
Moderately affected & 3 & $2-3$ & $80-160$ & $0.50-0.75$ & $>25-50 \%$ \\
Strongly affected & 4 & $3-5$ & $160-240$ & $0.25-0.50$ & $>50-75 \%$ \\
Seriously affected & 5 & $>5$ & $>240$ & $<0.25$ & $75-100 \%$ \\
\hline
\end{tabular}

*Averaged ratios of diversity index for algae, zooplankton and benthonic macroinvertebrates (pollution site/control site)

site (Zhu et al., 1994). Diversity indices for crustacean, rotifer, algae and protozoan communities were calculated using the Margalef diversity index (Margalef, 1957) as follows:

$$
d=\frac{S-1}{\ln N}
$$

where $S$ is the number of species, $N$ is the total number of individuals.

Diversity indices for benthonic macroinvertebrates were calculated using Shannon-Weaver diversity index (Shannon, 1949) as follows:

$$
\mathrm{H}=-\sum_{i}^{s}\left(\frac{n_{i}}{N}\right) \log _{2}\left(\frac{n_{i}}{N}\right)
$$

where $s$ is the number of species, $n_{i}$ is the total number of individuals in the $i$ th species and $N$ is the total number of individuals.

The toxicity tests with Photobacterium phosphoreum, Photobacterium Q67, algae $S$. obliqnus and $C$. vulgaris, and Daphnia magna, have been carried out to determine overall toxicity in different types of samples from Le An River, including river water, interstitial water, as well as sediment water extracts. In bioassay procedures, dissolved samples (water and interstitial water) were filtered through $0.45 \mu \mathrm{m}$ Millipore filter. Top sediment samples were centrifuged at $4000 \mathrm{r} / \mathrm{m}$ for 30 minutes to obtain the interstitial water (Backman J21 freezing centrifuge) Dried surface sediments were extracted by reconstructed river water according to the measured chemical composition. Bioassays were carried out according to relevant protocols and those developed in the laboratory (Zhou Y., 1989; Wang Z. et al., 1994; Wang and Tang, 1994; Ma et al., 1996).

\section{Classification of quality index}

Nemerow index (PI) for water pollution, Risk Index (RI) for sediment pollution, averaged ratio of diversity index of aquatic organisms, as well as relative inhibition or death rate from toxicity tests, were used to classify impact by heavy metals pollution in Le An River. In
Table 1, a hierarchical model was applied to rank the observed effects.

\section{RESULTS AND DISCUSSION}

\section{Heavy metal pollution and $p H$ in Le An River water}

The pH, Nemerow index (PI) and the major metal pollutants with their pollution index (I) are shown in Table 2. At A04, the $\mathrm{pH}$ was as low as 4.25 in the rainy season and 3.24 in the dry season, respectively. The $\mathrm{pH}$ along the river was similar both in the rainy and in the dry season. Strong acidity at A04 was due to receiving the mining acid drainage. In the rainy season, the dissolved $\mathrm{Cu}$ concentrations in most sampling sites exceeded the allowable levels (NS-SW-88 for type II water, GB 3838 or water quality criteria for aquatic culture, TJ-35-79). The pollution index of $\mathrm{Cu}$ was 2.9 at $\mathrm{AOl}$ and increased slightly at A04. Highest $\mathrm{Cu}$ and $\mathrm{Zn}$ concentrations were observed at $\mathrm{A07}$ ( $\mathrm{I}=\mathbf{8 . 9}$ and 3.1 for $\mathrm{Cu}$ and $\mathrm{Zn}$ respectively). In the dry season, the highest $\mathrm{Cu}$ concentration was observed at $\mathrm{A04}(\mathrm{I}=7.3)$, while it was relatively lower in other sampling sites. The highest $\mathrm{Zn}$ concentration was observed at A07 $(I=3.5)$. Concentrations of $\mathrm{Pb}$ were relatively lower along the river. The concentrations of $\mathrm{Pb}$ in dry season were higher $(I=1.1-1.3)$ than that in the rainy season $(I=0.1-0.3)$. Considering the chemical data, the river overlaying water was moderately polluted at $\mathrm{A} 01$ and $\mathrm{A} 04$ ( $\mathrm{PI}=2.2$ and 2.9 ) and heavily polluted at $\mathrm{A} 07$ (PI $=6.94)$ in the rainy season, mainly by $\mathrm{Cu}$ and partially by $\mathrm{Zn}$. In the dry season, the river water was heavily polluted at A04 $(\mathrm{PI}=5.57)$, mainly by $\mathrm{Cu}$ and $\mathrm{Pb}$, and moderately

\begin{tabular}{|c|c|c|c|c|c|c|}
\hline \multirow[b]{2}{*}{ Locations } & \multicolumn{3}{|c|}{ Rainy season (June, 1993) } & \multicolumn{3}{|c|}{ Dry season (Oct, 1994) } \\
\hline & $\mathrm{pH}$ & PI-value & Pollutant (I)* & $\mathrm{pH}$ & PI-value & Pollutants (I)* \\
\hline A01 & 7.65 & 2.20 & $\mathrm{Cu}(2.9)$ & 7.03 & 0.85 & $\mathrm{~Pb}(1.1)$ \\
\hline A05 & 6.66 & 0.99 & $\mathrm{Cu}(1.3)$ & 6.98 & 0.79 & $* *$ \\
\hline A07 & 6.65 & 6.94 & $\operatorname{Cu}(8.9), \operatorname{Zn}(3.1)$ & 7.10 & 2.81 & $\mathrm{Zn}(3.5), \mathrm{Pb}(1.2)$ \\
\hline A08 & 6.89 & 1.47 & $\mathrm{Cu}(1.9)$ & 7.09 & 0.84 & $* *$ \\
\hline
\end{tabular}

Table 2. Nemerow index, major pollutants and $\mathrm{pH}$ in river water

*Values in the parentheses are the concentration ratio of the measured value to water quality criteria. The criteria is adapted from NSSW88 for type II water. GB $3838-88$ or water quality criteria for aquatic culture, TJ35-79, $\mathrm{Cu}: 0.01 \mathrm{mg} / \mathrm{l}, \mathrm{Pb}: 0.05 \mathrm{mg} / \mathrm{l}, \mathrm{Zn}: 0.1 \mathrm{mg} / \mathrm{l}$. **Measured concentrations of metals were below their quality criterion.

-Not sampling 

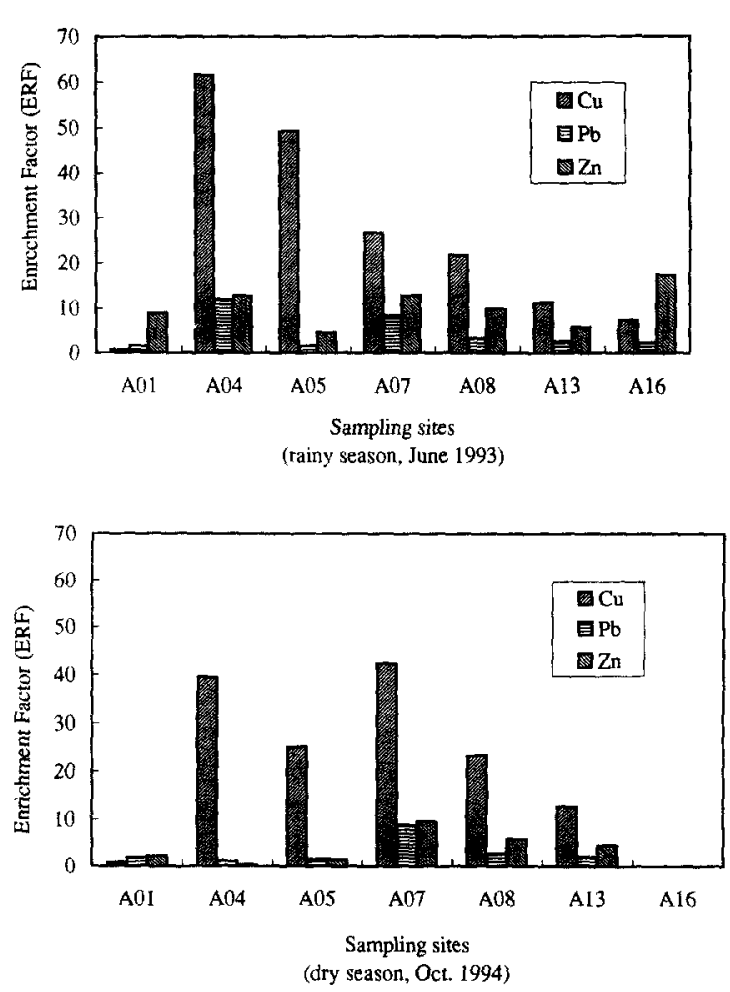

Fig. 2. Enrichment factor of copper, zinc and lead in sediments of Le An River.

polluted at $\mathrm{A} 07(\mathrm{PI}=2.81)$, mainly by $\mathrm{Zn}$ and $\mathrm{Pb}$.

Sediment pollution and evaluation by ecological risk index

The regional backgrounds of metals in Le An River were 34,117 and $45 \mathrm{mg} / \mathrm{kg}$ for $\mathrm{Pb}, \mathrm{Zn}$ and $\mathrm{Cu}$, respectively. Accordingly, the sediments of Le An River were heavily polluted by heavy metals. Metals that had sediment concentrations significantly above their backgrounds $(E R F \gg 1$ ) were $Z n$, $\mathrm{Pb}$ and especially $\mathrm{Cu}$ (Fig. 2). At site A01, the ERF was $0.71,1.57$ and 8.89 for $\mathrm{Cu}, \mathrm{Pb}$ and $\mathrm{Zn}$ in the rainy season, and $0.82,1.86$ and 2.24 for $\mathrm{Cu}, \mathrm{Pb}$ and $\mathrm{Zn}$ in the dry season, respectively. Higher ERF for $\mathrm{Zn}$ at site A01 might be caused by discharges from a small factory producing active carbon. At site A04, the ERF of $\mathrm{Cu}$ reached the highest, i.e. 61.53 and 39.53 in the rainy season and in the dry season, respectively. At site A07, the ERF of $\mathrm{Cu}$ and $\mathrm{Zn}$ were 26.87 and 12.83 in the rainy season and 42.36 and 9.63 in the dry season, respectively. From site $\mathrm{A} 08$ to $\mathrm{A} 16$, the ERF of $\mathrm{Cu}$ decreased remarkably. At site A13, the ERF were 11.2, 2.51 and 5.73 in the rainy season, and 12.69, 2.11 and 4.54 in the dry season for $\mathrm{Cu}, \mathrm{Pb}$ and $\mathrm{Zn}$, respectively.

The ecological risk indices were calculated for assessing the multiple metal pollution. As shown in Fig. 3 for the risk index (RI), heavy pollution of the sediments was expected between A04 and A07, and the highest occurred at A04 in the rain season and at A07 in the dry season. This was indicative that Dexing copper mine and mines along the Jishui River contributed significant inputs of heavy metals to the sediment. The sediment pollution was strong between $\mathrm{A} 04$ and $\mathrm{A} 07$, moderate between $\mathrm{A} 08$ and $\mathrm{A} 13$, and slight to moderate between $\mathrm{A} 13$ and A16. Obviously, the dilution effect exists in the sediment.

\section{Metal concentration in the interstitial water}

Metal concentration in the interstitial water of surface sediment in the rainy season (1993) is shown in Fig. 4. At site A01, the metal concentrations of $\mathrm{Cu}$ and $\mathrm{Pb}$ were 1.75 and $2.99 \mu \mathrm{g} / \mathrm{l}$. Concentration of $\mathrm{Cu}$ reached $23.8 \mu \mathrm{g} / \mathrm{l}$ at $\mathrm{A} 07$. At $\mathrm{A} 08, \mathrm{Al} 3$ and A16, the concentrations of copper were $19.4,19.5$ and $10.0 \mu \mathrm{g} / 1$, respectively.

Concentrations of zinc in the interstitial water were below the detection limit at A01, A05 and A16. They were 9.9 (A08) and $48.7 \mu \mathrm{g} / 1$ (A13). In all sampling sites, the concentration of lead in inter-

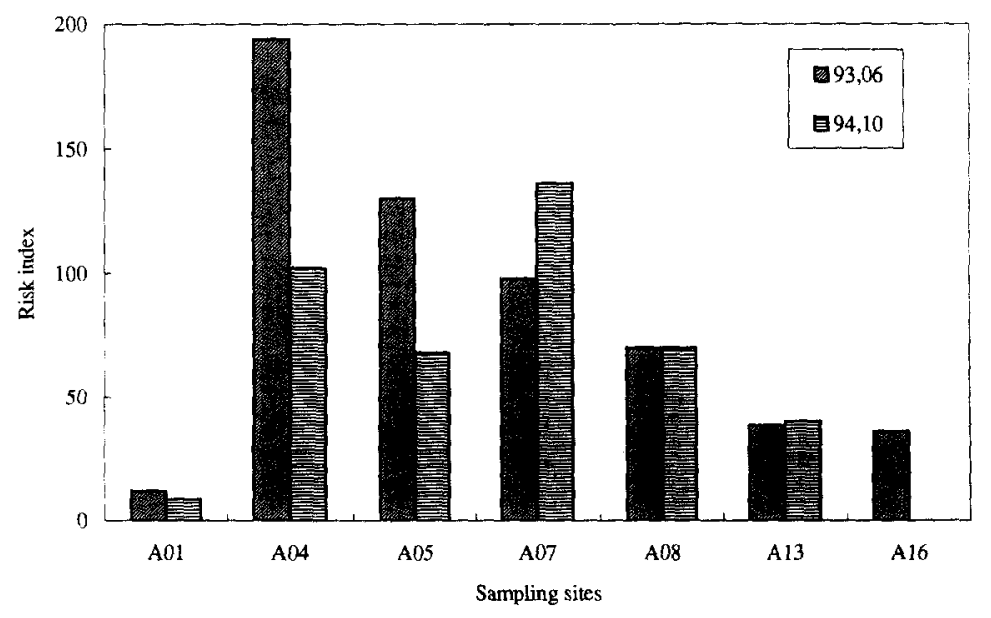

Fig. 3. Risk index values for sediment pollution. 


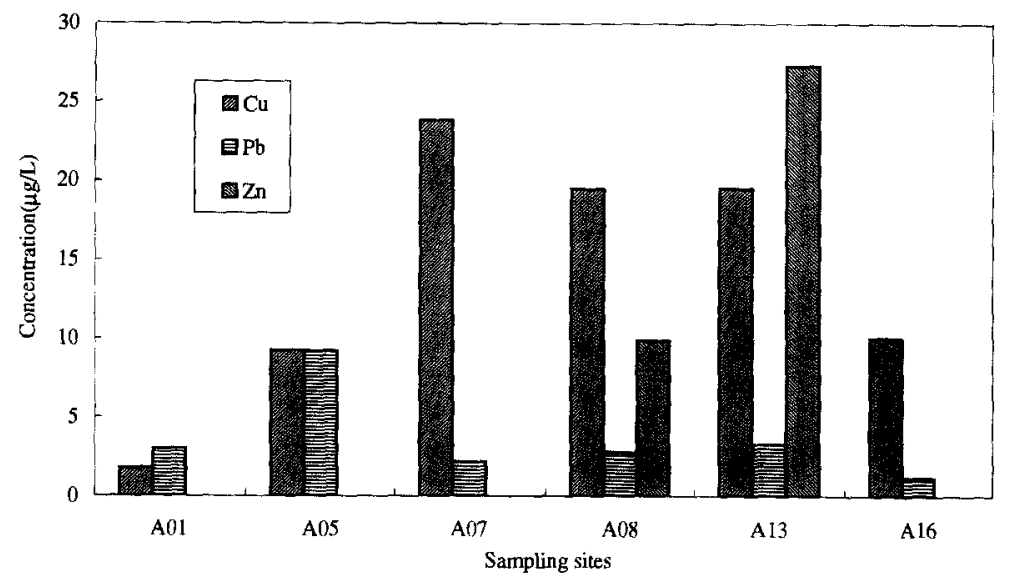

Fig. 4. Metal concentration in interstitial water of sediments (concentrations in $\mu \mathrm{g} / \mathrm{l}$ ).

stitial water was fairly low, and generally lower than $9.2 \mu \mathrm{g} / 1$.

The analysis for concentrations of heavy metals in the interstitial water showed that the concentrations of heavy metals were higher in downstream of the river (from A07 to A13) than in upstream of the river (at A05). It showed that the heavy metals in sediments were relatively stable. Additionally, the analysis of a core sample taken at A13 showed that the concentration gradients of $\mathrm{Cu}, \mathrm{Pb}, \mathrm{Cd}$, and $\mathrm{Zn}$ were not being leached from the sediments to the overlaying water but were rather diffused to the sediments (Yahya and Song, 1994). Therefore heavy metal pollution in the interstitial water would be more likely to have influence on the benthonic communities than on the overlaying water organisms.

Toxicity of river water, interstitial water and sediment extracts

According to the toxicity classification (Table 1), the results of bioassays for different kinds of samples were summarized in Table 3. Bioassay by photobacterium $T 3$ showed that, in the rainy season, the overlaying water at A01 was slightly toxic. At A04 and A05, no toxicity could be observed. The most toxicity occurred at A07 (relative inhibition of $84 \%$ ). In the dry season, toxicity of overlaying water assayed by photobacterium Q67 was shown to be slightly toxic at A01, moderately toxic at A04, and strongly toxic at A07.

The toxicity of interstitial water assayed photobacterium $T 3$ indicated that slight toxicity was observed at $\mathrm{A} 0 \mathrm{I}$ and $\mathrm{A} 05$, strong toxicity at $\mathrm{A} 07$ (relative inhibition of $69 \%$ ), and moderate toxicity at $\mathrm{A} 08$ and $\mathrm{A} 16$.

By D. magna acute toxic bioassay, strong toxicity has been observed for all sediment samples taken in the rainy season, and for samples of only DWR, J.R. (a sample taken from $100 \mathrm{~m}$ upstream of $\mathrm{A} 07$ in Jishui River) and A07 in the dry season.

Bioassays carried out by algae $S$. obliqnus and $C$. vulgaris for sediment extracts showed no toxicity or slight toxicity at A01, A04 and A05. Moderate to strong toxicity were observed at A07. No toxic effects were observed for samples of A08 and slight toxicity were observed for samples of A13.

According to the results from bioassays, one can conclude that the toxic discharge was mainly from Jishui River, instead of from Dexing copper mine,

Table 3. Ranked toxicity of overlying water, interstitial water and sediment extracts*

\begin{tabular}{|c|c|c|c|c|c|c|c|c|c|c|}
\hline Sampling sites & & A01 & DWR & A04 & A05 & J.R. & $\mathrm{A} 07$ & A08 & A 13 & A16 \\
\hline \multirow[t]{2}{*}{ Overlying water } & $1993^{a}$ & 2 & - & 1 & 1 & - & 5 & 2 & 2 & 2 \\
\hline & $1994^{b}$ & 2 & $\ldots$ & 3 & 2 & 5 & 5 & 3 & 3 & - \\
\hline Interstitial water & $1993^{a}$ & 2 & - & - & 2 & $\cdots$ & 4 & 3 & 3 & 3 \\
\hline \multirow[t]{3}{*}{ Sediment extracts } & $1993^{\circ}$ & 5 & - & - & 4 & $\cdot-$ & 5 & 5 & 5 & 5 \\
\hline & $1993^{d}$ & 2 & - & 2 & 2 & - & 3 & 1 & 1 & $\cdots$ \\
\hline & $1993^{\mathrm{e}}$ & 1 & - & 1 & 1 & - & 3 & 1 & 2 & $\cdots$ \\
\hline \multirow[t]{4}{*}{ Sediment extracts } & $1994^{\mathrm{a}}$ & 1 & 3 & 2 & - & 2 & 4 & 1 & 2 & $-\cdot$ \\
\hline & $1994^{b}$ & 2 & 3 & 1 & - & 5 & 5 & 3 & 2 & - \\
\hline & $1994^{\circ}$ & 1 & 5 & 2 & - & 5 & 5 & 2 & 1 & $\cdots$ \\
\hline & $1994^{c}$ & 1 & 2 & 1 & - & 4 & 3 & 1 & 2 & -- \\
\hline
\end{tabular}

*Toxicity was ranked according to the classification in Table 1.

${ }^{a}$ By Photobacterium phosphoreum bioassay, methodology refers to Wang $\mathrm{Z}$ et al., 1994;

'By Photobacterium Q67 bioassay, methodology developed by Ma et al., 1996;

${ }^{\complement}$ By D. magna acute toxicity bioassay $(\mathrm{S}: \mathrm{W}=1.9 ; \mathrm{g} / \mathrm{v}$ ), methodology refers to Zhou $\mathrm{Y} ., 1989$ and Wang $\mathrm{H}$ et al., 1994

${ }^{\mathrm{d}}$ By $C$. vulgaris growth inhibition bioassay ( $\mathrm{S}: \mathrm{W}=1.9 ; \mathrm{g} / \mathrm{v}$ ), methodology refers to Zhou $\mathrm{Y} ., 1989$ and Wang $\mathrm{H}$ et al., $1994 ;$

${ }^{e}$ By $S$. obliqnus growth inhibition bioassay $(\mathrm{S}: \mathrm{W}=1.9 ; \mathrm{g} / \mathrm{v})$, methodology refers to Zhou $\mathrm{Y} ., 1989$ and Wang $\mathrm{H}$. ef al., 1994 ; -not sampling 


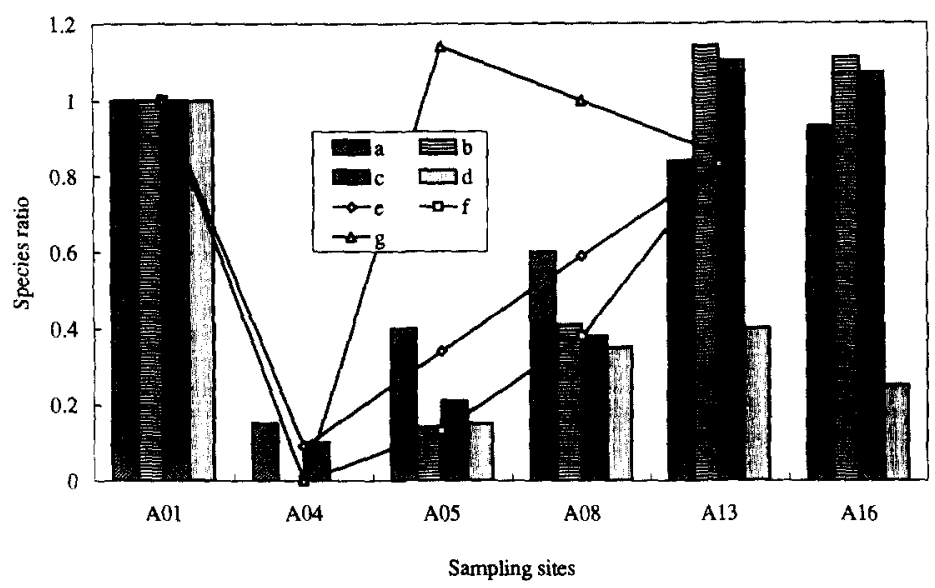

Fig. 5. Ratio of species richness (pollution site/control site) in the rainy and in the dry season; $\mathbf{a}, \mathbf{b}, \mathbf{c}$ and $d$ represent the algae, protozoa, zooplankton and benthos in the rainy season (June 1993), respectively; e, $\mathbf{f}$ and $\mathbf{g}$ represent algae, zooplankton and benthos in the dry season (Oct. 1994), respectively.

and that the sediment pollution had a potentially strong impact on the plankton community.

Ecological assessment on phytoplankton, zooplankton and benthonic macroinvertebrate community

Two hundred and thirty-two (232) plankton species were identified in the water samples and on the polyurethane substrates. The plankton species consisted of 123 species of algae, 32 species of crustacean, 19 species of rotifer and 58 species of protozoa in the rainy season (Xu et al., 1994). The benthonic species consisted of 26 and 20 species in the rainy and dry season, respectively (Zhu et al., 1994).

Variations regarding the ratio of species numbers and ratio of diversity index (pollution sites/control sites) for algae, zooplankton (crustacean and rotifer), protozoa and benthonic macroinvertebrate in the rainy and dry season are shown in Fig. 5 and Fig. 6, respectively. It can be seen from the figures that ecosystem deterioration was significant at $\mathrm{A} 04$ and $\mathrm{A} 05$, while a gradual recovery was observed from $\mathrm{A} 08$ to $\mathrm{A} 16$.

From the point of view of ecology, the aquatic ecosystem has been seriously affected by Dexing copper mine; strong to moderate effects could be expected between A05 and A08, slight effect was shown downstream of the river. However, it should be noted that the biological migration from the lake may contribute to the recovered biodiversity at A13 and A16.

\section{Integrating the chemical, toxicological and ecological data}

Indices for chemical pollution of water (PI) and sediment (RI), ranked toxicity for overlaying water, as well as averaged ratio of diversity index, were classified according to Table 1 and summarized in Table 4. Because a battery of bioassay has been conducted for assessing the toxicity of sediments,

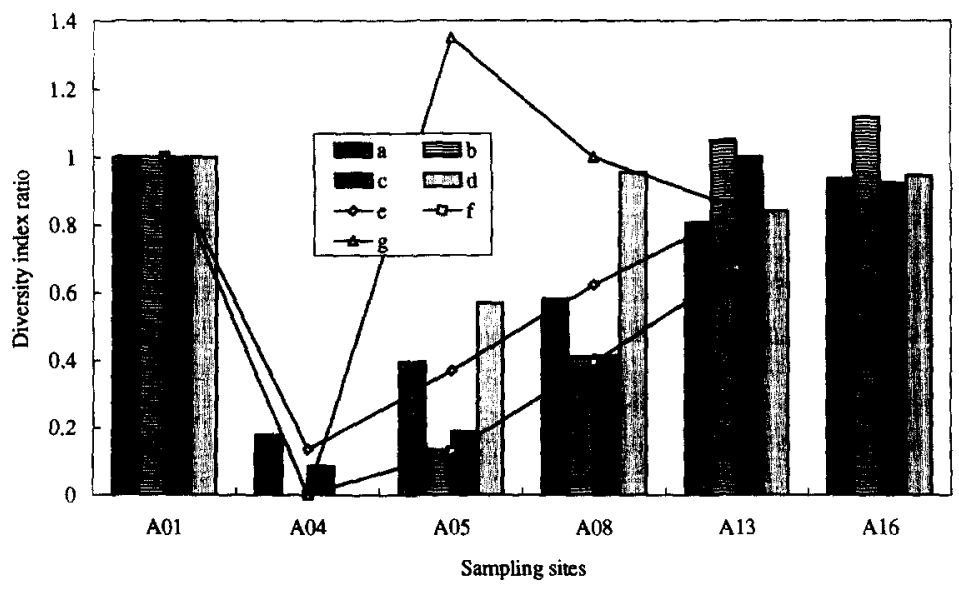

Fig. 6. Ratio of diversity index (pollution site/control site) in the rainy and dry season; $\mathbf{a}, \mathbf{b}$, $\mathbf{c}$ and $\mathbf{d}$ represent the algae, protozoa, zooplankton and benthos in the rainy season (June 1993), respectively; $\mathbf{e}$,

f and $\mathbf{g}$ represent algae, zooplankton and benthos in the dry season (Oct. 1994), respectively. 
Table 4. Classification regarding the chemical, ecological and toxicological assessments for Le An River*

\begin{tabular}{|c|c|c|c|c|c|c|c|c|}
\hline Sampling sites & & A01 & A04 & A05 & A07 & A08 & A13 & A16 \\
\hline Chemical pollution of water & 1994 & 1 & 5 & 1 & 3 & 1 & 1 & - \\
\hline Chemical pollution of sediment & 1994 & 1 & 4 & 3 & 5 & 3 & 2 & - \\
\hline \multirow[t]{2}{*}{ Toxicity bioassay of water } & 1993 & 2 & 1 & 1 & 5 & 2 & 2 & 2 \\
\hline & 1994 & 2 & 3 & 2 & 5 & 3 & 3 & - \\
\hline \multirow[t]{2}{*}{ Ecological assessment } & 1993 & 1 & 5 & 4 & - & 3 & 2 & 2 \\
\hline & 1994 & 1 & 5 & 3 & - & 3 & 2 & - \\
\hline
\end{tabular}

*Indices for chemical pollution of water (PI) and sediment (RI), ranked toxicity for overlaying water, as well as averaged ratio of diversity index were classified according to Table 1.

** Geometric means were used to integrate the multi-species bioassay data.

-Not sampling

geometric means were used to integrate the toxicity data before classification (Table 4).

Based on chemical, biological and ecological information, metal pollution and its impacts in Le An River could be explained as follows. At A01, while the index for water chemistry and bioassays proved to be slightly-to-moderately polluted in the rainy season, the ecosystem is still healthy (ecological assessment showed no alteration), due to its tolerability. The observed sediment toxicity on $D$. magna might be caused by high concentration of zinc (EC so $_{\text {for }} \mathrm{Zn}$ is $0.54 \mu \mathrm{g} / \mathrm{l}$; Khangarot and Ray, $1987)$ in the rainy season.

At $\mathrm{A} 04$, the river receives the acid mine drainage and the river water and sediment were heavily polluted. Meanwhile the structure and functions of the aquatic ecosystem were seriously damaged. The results of chemical and ecological assessments were consistent and both were shown to be heavily altered. However, results from the bioassay of river water and sediment extracts showed slight to moderate toxicity., Consequently, the deterioration could be caused rather by lower $\mathrm{pH}$ than by heavy metals pollution. This could be true also because the pH of media before bioassay has been adjusted to neutral condition. The additional evidences include that $\mathrm{Cu}$ associated forms in the sediment of A04, by chemical sequential extraction, was found mainly by inert fractions. The extractable $\mathrm{Cu}$ by water was very limited (Mao et al., 1992). There was no detectable electrochemical labile $\mathrm{Cu}$ in dissolved samples, by the double acidification anoxic stripping voltametric determination (unpublished data). A similar explanation could be drawn for sampling location A05 (20 km downstream of A04), except that the tension was slightly relaxed due to dilution.

At A07, various assessments showed similar conclusions: the metals pollution induced adverse effects and resulted in serious impacts on the ecosystem.

From A08 to A16, the chemical assessment for overlaying water showed no pollution, while the toxicological and ecological assessments for river water and sediments proved to be affected slightly to moderately. Downstream A08, the aquatic ecosystem was slowly reviving from serious deterioration, due to the buffer capacity of water and sediment, the dilution effects, and the supplementary migration of biological species from the lake. However, potential effects induced by sediment pollution is expected and it will happen when hydrological (like agitation and dredge activities) and physicochemical (like $\mathrm{pH}$ and $\mathrm{p} \varepsilon$ variation) conditions are varied.

Comparing the difference of chemical, ecological and toxicological data between the dry and the rainy season, the pollution of river water was more serious in the rainy season than in the dry season. The pollution of sediment at the upstream of the river was more serious in the rainy season than in the dry season owing to the pollution from the Dawu River, and was more serious in the dry season than in the rainy season at A07 owing to the pollution from the Jishui River. From A08 to A16, the sediments were slightly to moderately polluted owing to sediment migration and dilution. The results of ecological assessment were quite similar in the rainy season and in the dry season. The toxicity of river water was relatively higher in the dry season than in the rainy season. However, the toxicity of sediment was very similar in the two periods.

\section{CONCLUSIONS}

The river water and sediment pollution in the Le An River have affected the aquatic ecosystem, mainly between sites A04 and A07, indicating clearly two sources of discharges into the river. Sediment pollution was associated with moderate biological and ecological deterioration prevailing in downstream of the river as far as the delta of the lake. The controlled mechanism behind the observed ecological effects of heavy metal pollution could be attributed to the stability of sediment bound metals (Wen and Herbert, 1996a; Wen and Herbert, 1996b), mineralization (Dai et al., 1994), flocculation and coagulation (Luan et al., 1994), the bioavailability (Mao, 1996), as well as that of hydrological conditions (like diffusion and dilution). 
Table 5. Description of the impacts of heavy metal pollution

\begin{tabular}{|c|c|c|}
\hline Location (distance) & Description & Recommendation \\
\hline $\mathrm{A} 01-\mathrm{A} 04(20 \mathrm{~km})$ & $\begin{array}{l}\text { Slight-to-moderate Zn pollution causes toxicity to } \\
\text { sensitive species, but has not affected the ecosystem } \\
\text { Sediment is seriously polluted by heavy metals and } \\
\text { most of the metals in the sediment are not }\end{array}$ & $\begin{array}{l}\text { Discharges from the active-carbon manufacture should } \\
\text { be controlled }\end{array}$ \\
\hline $\begin{array}{l}\mathrm{A} 04-\mathrm{A} 05(20 \mathrm{~km}) \\
\mathrm{A} 05-\mathrm{A} 07(10 \mathrm{~km})\end{array}$ & $\begin{array}{l}\text { bioavailable. Serious system deterioration should be } \\
\text { caused by acidity discharge. } \\
\text { System is slowly recovered due to dilution and } \\
\text { neutralization processes. }\end{array}$ & $\begin{array}{l}\text { More attention should be addressed to acid mine } \\
\text { drainage and accidental discharges }\end{array}$ \\
\hline A07-A08 (34 km) & $\begin{array}{l}\text { This is the most endangered part of river and is } \\
\text { seriously polluted, mostly toxic, and deteriorating. } \\
\text { Sediments are slightly-to-moderately polluted and }\end{array}$ & $\begin{array}{l}\text { Controlling discharges from mines and smelters along } \\
\text { the Jishui River is urgent. }\end{array}$ \\
\hline$A 08-A 16^{*}(146 \mathrm{~km})$ & $\begin{array}{l}\text { potential sediment toxicity exists. System is } \\
\text { undergoing recovery owing to dilution and species } \\
\text { migration from the lake. }\end{array}$ & $\begin{array}{l}\text { Dredging and relevant activities should be careful. } \\
\text { Attention should be addressed to variation of } \\
\text { physico-chemical conditions of the river. }\end{array}$ \\
\hline
\end{tabular}

*There is an abundant small mine at $100 \mathrm{~km}$, which also introduces metal pollutants.

Detailed information can be found in relevant publications of CERP

Table 5 lists the locational specific conclusions based on the integrated results. By comparison of results of chemical, toxicological and ecological assessments, it was concluded that discharges from Dexing copper mine and mines along the Jishui River have resulted in a significant increase of the concentration of copper, zinc and lead in water and sediments along the Le An River and a lower $\mathrm{pH}$ at A04. The authors believe, therefore, that the management of metal discharges from the Jishui River and acid drainage from the Dexing copper mine should be addressed as a priority. The mining activity in the area has caused ecosystem deterioration for at least $64 \mathrm{~km}$ from A04 and has a potential impact for a further $146 \mathrm{~km}$ downstream as hydrological conditions are varied.

This study also illustrates that any of the chemical, toxicological and ecological assessments have disciplinary limitations, and that an integration could be useful for better understanding of the impact of heavy metal pollution on an aquatic ecosystem.

Acknowledgements-The authors would like to thank the participants in the project, who provided also the data for this paper. We cannot list their names because a total of more than 20 scientists contributed to the work (including scientists from Germany). Special thanks are due to German BMBF and Chinese CAS for providing funding support and to Dr. Thomas Schaaf in the Paris office of UNESCO and Prof. Zhao Xiangyin from Chinese MAB for coordinating the project. Special thanks are also due to Prof. German Müller of Heidelberg University, Germany, who was one of the principal investigators in the project.

\section{REFERENCES}

Birge W. J., Black J. A. and Westerman A. G. (1985) Short-term fish and amphibian embryo-larval tests for determining the effects of toxicants stress on early life stages and estimating chronic values for single compounds and complex effluents. Environ. Toxicol. Chem. $4,807-821$.

Cairns J. Jr (1980) Estimating hazard. Bio. Sci. 30, 101-107.
Dai Z., Starke R., Kleeberg R., Wang X. and Liu Y. (1994) Physicochemical properties of Le An river sediments. China Environ. Sci. 5, 129-134.

Khangarot B. S. and Ray P. K. (1987) Correlation between heavy metal acute toxicity values in Daphnia magna and fish. Bull. Environ. Contam. Toxic. 38, 722 726.

Kramer K. J. M. and Botterweg J. (1991) Aquatic biological early warning system: an overview. In Bioindicators and Environmental Management (edited by Jeffrey D. W. and Madden B.). Academic Press, New York.

Lars H. (1980) An ecological risk index for aquatic pollution control: A sedimentological approach. Wat. Res. 14, 975-1001.

Leland H. V., Fend S. V. and Dudley T. L. (1989) Effect of copper on species composition of benthic insects in a Sierra Nevada. California stream. Freshwat. Biol. 21, 163-179.

Lin Y., Li Q., Zou G. and Shi S. (1992) Impacts of acid mine drainage on water quality of Le An River and Poyang Lake area. J. Environ. Sci. (in Chinese) 4, 4-13.

Luan Z., Klute R., Hahn H. and Tang H. (1994) The stability and aggregation of fine-grained ore tailing, hydrous $\mathrm{Fe} / \mathrm{Al}$ oxides and their binary mixtures in natural water. China Environ. Sci. 5, 149-158.

Luoma S. N. (1983) Bioavailability of trace metals to aquatic organisms: a review. Sci. Total Environ. 28, 122.

Luoma S. N. (1990) Processes affecting metal concentrations in estuarine and coastal marine sediments. In Heavy Metals in the Marine Environment (edited by Rainbow P. S. and Furness R. W.). CRC Press, Cleveland, Ohio.

Ma M., Tong Z., Wang Z., Yang D. and Zhu W. (1996) Application of new type of fresh water Lumino Bacterium (Vibrio qinghaiensis sp.-Q67) for toxic bioassay. Acta Sci. Circ.

Mao M. (1996) Speciation of metals in sediments along the Le An River. In the Final Report of the Co-operative Ecological Research Project (CERP). pp. 1-57. Published in 1996 by the United Nations Educational, Scientific and Cultural Organisation.

Mao M., Lui Z. and Dong H. (1992) Distribution and speciation of metals in sediments along Le An River. $J$. Environ. Sci (China) 4 (3), 72-81.

Margalef R. (1957) Information theory in ecology. Mem. real acal. 3rd ser. Barcelona 32, 374-449.

Müller G. and Tang H. (1996) Ecological effects of heavymetal pollution in the Dexing Copper Mine region in Jiangxi Province, China. in the Final Report of the Cooperative Ecological Research Project (CERP). 
Published in 1996 by the United Nations Educational, Scientific and Cultural Organization.

Phillip R. C. (1989) Water quality, sediments and the macroinvertebrate community of residential canal estates in south-east Queensland, Australia: a multivariate analysis. Wat. Res. 23, 1087-1097.

Qi S. and Huang W. (1993) The benthic macroinvertebrate community relating to the water quality in lower Zhujiang (Pearl River). Acta Sci. Circum. (in Chinese) $13(1), 80-86$.

Shannon C. (1949) The Mathematical Theory of Communication. Univ. Illinois Press, Urbana. 49-73.

Soomi L., Suziki M., Tamiya E. and Karube I. (1990) Microbial detection of toxic compounds utilizing recombinant DNA technology and bioluminescence. Anal. Chimi. Acta 244, 201-206.

Tang H., Wang Z., Liu J. and Müller G. (1994) Ecological impacts of heavy metal pollution from Dexing Copper Mine to Poyang Lake-Recent research progress in CERP-continual phase. China Environ. Sci. 5 (2), 97101.

Monteiro M. T., Oliveira R. and Vale C. (1995) Metal stress on the plankton communities of Sado River (Portugal). Wat. Res. 29, 695-701.

Wang $H$. and Tang $H$. (1994) Toxic effects of the polluted sediments in Le An River on Hydrobios. China Environ. Sci. 5, 165-168.

Wang Z., Ma M., Du Q and Wen X. (1994) Toxic assessment by Photobacterium phosphoreum. China Environ. Sci. 5, 159-164.
Wen X. and Herbert E. A. (1996a) The acid and base properties of Le An River sediment and their influence on the release of heavy metals contained in sediment samples. Environ. Chem. (in Chinese).

Wen X. and Herbert E. A. (1996b) Acid-volatile-sulfide (AVS) in Le An River sediment and the effect of oxygen on the release of heavy metals in the sediment. Environ. Sci. (in Chinese).

Wesley J. B., Jeffrey A. B., Terry M. S. and Albert G. W. (1989) A comparative ecological and toxicological investigation of a secondary wastewater treatment plant effluent and its receiving stream. Environ. Toxicol. Chem. 8, 437-450.

Xu M., Gao Y., Ma M. and Wang Z. (1994) The relationship between the changes of plankton community structure and the metal pollution in Le An River. China Environ. Sci. 5, 172-176.

Yahya A. and Song Y. (1994) Distributions of heavy metals in sediments and pore waters of Le An River at Caijiawang. China Environ. Sci. 5, 105-109.

Yang S. (1987) Zoobenthos investigation and water quality biological assessment in the mainstream of Tuojiang River. Environ. Sci. 8 (5), 50-55.

Zhou Y. (1989) Experimental methods for toxic assessment of aquatic biota. Agricultural publisher, China. p. 190.

Zhu J., Ren S., Lin Z. and Lin Y. (1994) Preliminary study on the benthic macroinvertebrate community relating to the metal pollution in Le An River. China Environ. Sci. 5, 177-181. 